\title{
The Factors Leading to Repeat Visitation of Domestic Tourists to Phitsanulok Province Thailand
}

\section{Phisunt Tinakhat, Ahmad Mujafar Syah, Andris Adhitra, Rachatawan Limkanchanapa, Varintorn Viriyachaikul, Anna Stepanova}

International Tourism and Hospitality Management Program, Naresuan University International College, Phitsanulok, Thailand

\section{Email address:}

phisuntt@nu.ac.th (P. Tinakhat), ahmadmu@nu.ac.th (A. M. Syah), andrisa@nu.ac.th (A. Adhitra),

rachatawanl@nu.ac.th (R. Limkanchanapa), varintornv@nu.ac.th (V. Viriyachaikul), annas@nu.ac.th (A. Stepanova)

\section{To cite this article:}

Phisunt Tinakhat, Ahmad Mujafar Syah, Andris Adhitra, Rachatawan Limkanchanapa, Varintorn Viriyachaikul, Anna Stepanova. The Factors Leading to Repeat Visitation of Domestic Tourists to Phitsanulok Province Thailand. Science Journal of Business and Management.

Vol. 8, No. 2, 2019, pp. 96-101. doi: 10.11648/j.sjbm.20200802.17

Received: July 16, 2019; Accepted: August 21, 2019; Published: May 28, 2020

\begin{abstract}
The purpose of this paper aims to study the factors leading to the repeat visitation of domestic tourists to Phitsanulok province, Thailand. The researchers adapted quantitative methodology by using the survey questionnaires to identify the factors influencing them to repeat the visit. A convenience sampling method is used to collect the data from the domestic tourists traveling to Phitsanulok from August to October 2018 for 400 subjects ( 250 women and 150 men). The questionnaire is judged by the 5 points Likert Scale. A result of this study revealed that the main top 3 reasons why they would like to repeat visit Phitsanulok because of the famous Buddha image (mean $=4.66, \mathrm{~S} . \mathrm{D} .=0.655)$, followed by a variety of natural attractions (mean $=4.29$, S. D. $=0.750)$, and quality accommodation at reasonable price (mean $=4.22, \mathrm{~S} . \mathrm{D} .=0.787)$, while the least factor is deal on package tours $(n=400)($ mean $=3.29)(S . D .=0.769)$. From the result of the conclusion show that further study should focus on deal on package tours because this study found that the least factor is deal on package tours in Phitsanulok by domestic Thai tourists so it improves to be more reasonable price of deal on package and keep stable the good points that make the tourists impressed in Phitsanulok. Moreover, some suggestions from the tourists is mainly about the accessibility to the tourism areas for the disabled and senior tourists. This is quite important and should be brought to the attention to tourism stakeholders in considering to improve this suggestion to be more efficient so it can attract more tourists not only domestic but also international. The researcher hope that this researcher will be beneficial to both private and public sectors in improving and developing the tourism infrastructures and services to attract more tourists in the future.
\end{abstract}

Keywords: Repeat Visitation, Domestic Tourists, Phitsanulok

\section{Introduction}

Phitsanulok has increasing grown last 5 years in number of tourist. Number of tourist has increased steadfast from 1.2 million in 2011 to 1.8 million in 2015 as in Figure 1 [8].

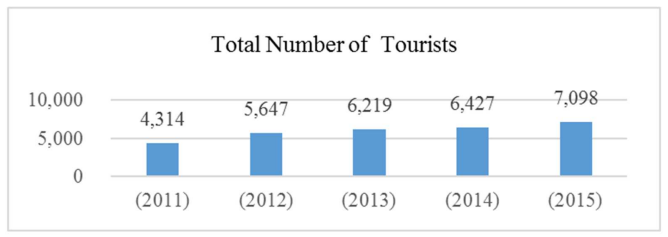

Source: National Statistical Office, 2017
Figure 2 shows the number of Thai tourists increase while the international tourists are declined.

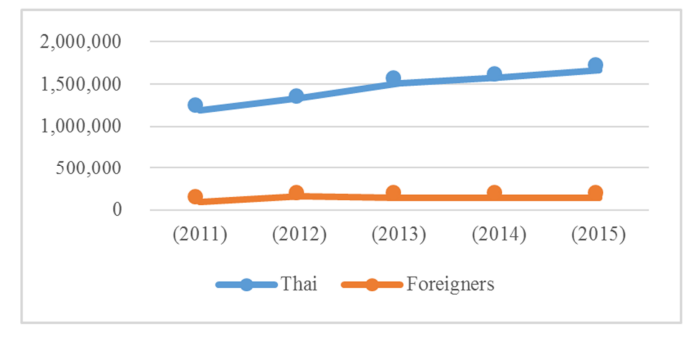

Source: National Statistical Office, 2017

Figure 2. Thai tourist arrivals in Phitsanulok, Thailand 2011-2015.

Figure 1. Total tourist arrivals in Phitsanulok, 2011-2015. 
Repeat visitation is important in the tourism industry. Most of the tourist destinations are mainly relying on the repeat visitors. The repeat visit will lead to the loyalty and the loyal visitors will spread their good experiences to other potential visitors to the destination [1]. There are many previous studies about the motivation of the tourists that lead to the repeat visitation to the certain places. Some articles has showed with the evidence that 2 percent of the revisit travelers can save the 10 percent of the overall cost of the tourist industry [5]. Repeat visitors are familiar with the destination than the first time visitors, therefore it is easier and less costly to serve them in term of services. Moreover, most of the repeat visitors stay at the destinations longer than the first time. The longer stay means the more income that will come into the tourism industry. The lesser cost to serve the repeat visitor plus the longer the duration of stay at the place will generate quite a lot of profit to the tourism industry [9].

Importantly, to understand the factors that influence the revisitation enables the destination tourism managers or authorities to better realise on how to develop the effective tourism marketing and strategies to manage and create the travel motivation to attract visitors [4]. Regarding the economic perspective, the study on repeat visitation is crucial for tourism business in operating more effectively and efficiently. In fact, attracting the previous visitors is more cost-effective than gaining the new ones [6] as the promotional costs in attracting the repeat visitors are certainly less than the first time visitors. Business tends to rely on loyal customers which act as a key role in driving the profitability to the business. Retaining the loyal visitors to revisit is highly important for generating the revenue in tourism destinations as well as reducing the marketing expenses [16].

Being one of the top destinations in Thailand, the repeat visitors to Phitsanulok is highly vital for increasing revenue for tourism industry in Thailand. Significantly, the in-depth study on the factors influencing the repeat visitors definitely provides a strong foundation to enhance the tourism market as it portrays profound understanding on the visitors' satisfaction. Moreover, it helps to identify the problems and strengthen goods and service quality in tourism industry. Being capable to enrich the key factors to fulfill the unmet needs of the visitors would sustainably allow destination to become the top of mind destination. This research will be focusing on the factors that lead to the repeat visitation of the domestic tourists to Phitsanulok. Brief literature reviews of the past studied about satisfaction, revisit intentions, destination loyalty and word-of-mouth factors will be mentioned and the researchers will use the questionnaires to collect the data and the finding and conclusions will be presented and discussed.

\section{Literature}

\subsection{Motivation}

According to Crompton [3], motivation is the main factor that the visitors select certain places to visit. If the visitors have not been to the place yet, the word-of-mouth and images of the places play the important role to motivate the visitor to select that place. The first time travel experiences will lead to whether the visitor will be motivated to revisit the place again. Moutinho [7] noted that the convenient transportation, natural beauty of the place and safety factors also play the important roles in order to motivate the visitors to select the place. The more understand the factors that make the visitor satisfy, the more you will be able to make the visitor to revisit the place [11].

\subsection{Destination Image}

The destination image is a concept created by different supply and demand agents about the balance between needs to be delivered as a necessity for promotion. The destination with the main goal is to create a brand image. The expectations and needs of tourists are shown in the travel blog of tourists and will include supply-side analysis through information from villagers and tour guides to gather ideas for ideas. And creating a look for tourist attractions. The destination image is one of the most researched topics in tourism because the image is something that has the power to create certain images in the minds of tourists about the image of attractions to attract tourists to come in. In the area and the image of the tourist attraction is important to the destination because the image of the tourist attraction has the power to change and make the tourists aware of the place and what determines the popularity of tourists [18].

Destination image identified that most driving factors have been received by tourist's needs, such as the need to escape, seeking adventure, fulfilling dreams, seeking novelty, relaxation, health, fitness and socialization. Motivation means, the combination of physical, mental, and cultural driving forces of well-being urging to show behavior of target consumers and as a motivation for tourism it represents experience of consumption behavior and tourism services at tourist attractions to meet the needs and satisfaction of tourists [16].

The destination of tourists with a variety of attractions is more important than individual attraction because of the better highway in recent years in China. Destination image Tourist satisfaction and loyalty to destinations are important factors that explain the motivation of the visitors that they intend to return to the tourist destination and the satisfaction of tourists is the evaluation of after-service reception. Service and depending on the destination image, all due to the amount of space developed for tourism racial in addition, today's tourists are also encouraged by increasing the time required for relaxation, increasing disposable income and efficient transportation networks, the ability and ability to choose a variety of destinations. Marketing tourism is experiencing problems in the decision-making of consumers in increasingly complex and growing markets [6].

\subsection{Destination Loyalty}

Destination Loyalty is the most important factor in the tourism business. He has reviewed more than 30 articles and found that the service quality and satisfaction have direct 
relationship with the Loyalty, the visitors measure the service quality with the cost that they pay for the services. Therefore, it is very important to serve the guest right in order to receive their loyalty. Therefore, in an increasingly competitive marketplace, the success of marketing destinations should be guided by a thorough analysis of tourist motivation and its interplay with tourist satisfaction and loyalty [14].

\subsection{Tourist Satisfaction}

It is difficult to make clear the meaning of tourist satisfaction in this study. There are lots of the definitions of satisfaction, it is recognized as a post-purchase behavior relating how much a consumer likes or dislikes a service or product after experiencing it [18]. The tourist satisfaction was the fundamental pillar of the marketing theory [17] and it was considered as a key influence for the intention's future purchase, market share and power of word-ofmouth [10]. The overall satisfation of the customers might be related to their assessment of not just only the service qualitybut also product features and price as well.

\subsection{Revisit Intention}

There are three factors in the visitor process perspective in Tourism [13]. They are pre-visiting, during visit and post visit. Pre-visiting is most important one because the visitor must choose to visit the destination first in order to experiences during visit and to be able to comment or decide the post visit feeling or satisfaction level. The visitor will select the place first then they will experience and evaluate the place during their visit and finally make the comments the places [2]. Those post visiting comments are very important because it will affect the future potential visitors to come to visit or not and even to the current visitors to revisit the place. Positive comment givers are mostly come back to the place and most of the first time visitors are likely to revisit the place due to those positive comments.

\section{Methodology}

This research adapted survey questionnaires from Rittachainuwat [12] to identify factors influencing repeat visitation to Phitsanulok. This research used convenience sampling method to collect the data. The 5 point like Scale questionnaires were used to collect the data of the research. 1 $=$ very bad to $5=$ very good.

After collecting the data from the questionnaires, the Social Science (SPSS) program was used to analyze the data collected.

Part 1 is the factors that motivate the visitors visit Phitsanulok.

Part 2, two questions related to revisit intentions were asked to the visitors in order to know the main points that lead the visitors to revisit Phitsanulok.

Part 3, The demographic factors include gender, marital status, occupation, income and education levels etc. and the last part is recommendation.
However, due to the time limitation, convenience sampling method was used to represent the whole population of domestic tourists that visit Phitsanulok. The questionnaires were collected in several tourist attractions in Phitsanulok

\subsection{Research Instruments}

The questionnaires were used to collect the data in this research. The questionnaires mainly focused on the motivation of the tourists that come to visit Phitsanulok, destination loyalty of the tourists visiting Phitsanulok, the factors influencing the intentions of tourists revisiting Phitsanulok, and the intention of visitors to recommend others to visit Phitsanulok by positive word-of-mouth from their experiences. The sample of this research is Thai tourists who are traveling in Phitsanulok, Thailand from August to October 2018. Then the research process is outlines as per its objectives as follows.

\subsection{Population}

Sample of this research is tourists who are traveling in Phitsanulok, Thailand. According to the Department of Tourism [15], the number of tourist traveling to Phitsanulok $1,813,705$ and this number was examine the population of this research.

\subsection{Sample Size}

Sample size of this research is tourist who are traveling in Phitsanulok by using the Yamane's formula [19]. Hence, the sample size was 400 subjects; however, to preclude incomplete answers on some of the questionnaires, 400 complete questionnaires were used in the analysis of the data.

\subsection{Variables}

Independent Variables: The independent variables are gender, age, marital status, educational level, occupation, province of residence.

Dependent Variables: motivation, recommendation and revisit to Phitsanulok.

\section{Result}

In order to analyze the data followed by the research finding 400 questionnaires. Firstly, the demographic factors consist of age, gender, educational background, income and occupation. Second, the summarized results of tourist would recommend to others and revisit in the future. Third, tourist motivation factors will effect to revisit Phitsanulok. Tourist motivation factors with a 5-item scale was measure by using Likert scale ranging from

$1=$ Very bad

$2=\mathrm{Bad}$

$3=$ Neutral

$4=$ Good

$5=$ Very good

To evaluate the tourist motivation influencing selection of factors in Phitsanulok. 
Part 1: Demographic Factors Analysis

Table 1. Gender.

\begin{tabular}{lll}
\hline Gender & Frequency & Percent $(\%)$ \\
\hline Male & 150 & 37.50 \\
Female & 250 & 62.50 \\
Total & 400 & 100 \\
\hline
\end{tabular}

Table 1 shows that there were 150 male $(37.50 \%)$ and 250 persons $(62.50 \%)$ of them were female.

Table 2. Age (years).

\begin{tabular}{lll}
\hline Age & Frequency & Percent $(\%)$ \\
\hline $20-25$ & 73 & 18.20 \\
$26-30$ & 195 & 48.80 \\
$31-35$ & 110 & 27.50 \\
Over 35 & 22 & 5.50 \\
Total & 400 & 100.00 \\
\hline
\end{tabular}

Table 2 shows that the majority Thai tourists came to Phitsanulok is 195 persons $(48.80 \%)$ of age group was between $26-30$ years old, followed by 110 persons $(27.50 \%)$ of them who were $31-35$ years old, 73 persons $(18.20 \%)$ who were between $20-25$ years old and 22 persons $(5.50 \%)$ of them were over 35 years old.

Table 3. Educational background.

\begin{tabular}{lll}
\hline Educational background & Frequency & Percent $(\%)$ \\
\hline College and under & 9 & 2.20 \\
Bachelor & 335 & 83.80 \\
Higher than bachelor & 56 & 14.00 \\
Total & 400 & 100.00 \\
\hline
\end{tabular}

Table 3 shows that there are 335 persons $(83.80 \%)$ most of them were bachelor's degree, higher than bachelor's degree were 56 persons $(14 \%)$ and 9 persons $(2.20 \%)$ of them were college and under.

Table 4. Occupation.

\begin{tabular}{lll}
\hline Occupation & Frequency & Percent $(\%)$ \\
\hline Government Staff & 93 & 23.25 \\
Company Staff & 116 & 29.00 \\
Business Owner & 88 & 22.00 \\
Students & 76 & 19.00 \\
Others & 27 & 6.75 \\
Total & 400 & 100.00 \\
\hline
\end{tabular}

Table 4 shows the occupation of Thai tourists who came to Phitsanulok. Most of them were company staff for 116 persons (29\%), 93 persons $(22.25 \%)$ were government staff, followed by business owner for 88 persons (22\%), students for 76 persons $(19 \%)$ and 27 persons $(6.75 \%)$ were others.

Table 5. Income.

\begin{tabular}{lll}
\hline Income (Baht per month) & Frequency & Percent $(\mathbf{\%})$ \\
\hline Lower than 15,000 & 24 & 6.00 \\
$15,001-25,000$ & 89 & 22.20 \\
$25,001-35,000$ & 174 & 43.50 \\
35,001 and above & 113 & 28.30 \\
Total & 400 & 100.00 \\
\hline
\end{tabular}

Table 5 shows the income of Thai tourists who came to Phitsanulok. 174 persons $(43.50 \%)$ have income between 25,001-35,000 baht per month, over 35,001 baht per month of 113 persons $(28.30 \%), 89$ persons $(22.20 \%)$ were between $15,001-25,000$ baht per month and 24 persons $(6 \%)$ less than 15,000 baht per month.

Part 2: Tourist's behavior information

Table 6. I will revisit Phitsanulok in the future.

\begin{tabular}{lll}
\hline I will revisit Phitsanulok in the future & Frequency & Percent $(\%)$ \\
\hline Yes & 400 & 100 \\
No & 0 & 0 \\
Total & 400 & 100.00 \\
\hline
\end{tabular}

Table 6 shows all 400 Thai tourists $(100 \%)$ will revisit Phitsanulok in the future

Table 7. I would recommend Phitsanulok to others.

\begin{tabular}{lll}
\hline I would recommend Phitsanulok to others & Frequency & Percent $(\%)$ \\
\hline Yes & 400 & 100 \\
No & 0 & 0 \\
Total & 400 & 100.00 \\
\hline
\end{tabular}

Table 7 shows the amount of Thai tourist would recommend Phitsanulok to others. All of them would recommend Phitsanulok.

Part 3: Tourist motivation
This part analyzes level of agreement about tourist motivation in Phitsanulok. The result shows mean $(\overline{\mathrm{x}})$ and standard deviation (S.D.). Interval scale used to analyze level of agreement as following.

Table 8. Tourist motivation.

\begin{tabular}{llll}
\hline Tourist Motivation & Mean & Std. Dev & Level \\
\hline Shopping & 3.82 & 0.753 & Good \\
Thai Food & 3.95 & 0.697 & Good \\
Health care & 3.91 & 0.736 & Good \\
Quality of food & 4.06 & 0.778 & Good \\
Service-mined people & 4.00 & 0.751 & Good \\
\hline
\end{tabular}




\begin{tabular}{llll}
\hline Tourist Motivation & Mean & Std. Dev & Level \\
\hline Spa & 3.76 & 0.919 & Good \\
Quality accommodation at reasonable price & 4.22 & 0.787 & Very Good \\
Famous Buddha image & 4.66 & 0.655 & Very Good \\
A variety of natural attractions & 4.29 & 0.750 & Very Good \\
Price & 4.05 & 0.656 & Good \\
Interesting culture & 3.98 & 0.708 & Good \\
New travel experience & 3.96 & 0.763 & Good \\
Seeing people from different culture & 3.84 & 0.758 & Good \\
Overall variety of thing to do & 3.80 & 0.752 & Good \\
Interest landscape & 3.81 & 0.764 & Good \\
Tourist Motivation & Mean & Std. Dev & Level \\
Safe travel destination & 3.80 & 0.749 & Good \\
Different Climate than that at home & 3.71 & 0.779 & Good \\
Adult entertainment & 3.63 & 0.827 & Good \\
Stable political situation & 3.58 & 0.803 & Good \\
Deals on package tours & 3.29 & 0.769 & Neutral \\
Total & 3.91 & 0.758 & Good \\
\hline
\end{tabular}

4.21-5.00 = Very good

$3.41-4.20=$ Good

$2.61-3.40=$ Neutral

$1.81-2.60=\mathrm{Bad}$

$1.00-1.80=$ Very bad

Table 8 shows that the main reason why Thai tourist want to repeat visit Phitsanulok because of the famous Buddha image (mean=4.66), followed by a variety of natural attractions (mean=4.29) while the least factor is deal on package tours $(\mathrm{n}=400)($ mean $=3.29)($ S.D. $=0.769)$.

\section{Conclusion}

The results of this research show about the factors that motivated Thai tourists to visit to Phitsanulok. The most of the tourists were feeling satisfy and they would revisit and recommend to others about good experience in Phitsanulok. Moreover, the mainly motivated tourists are famous Buddha image, a variety of natural attractions and quality accommodation at reasonable price.

According to the result well-known famous Buddha image is the first thing that motivate tourists to visit Phitsanulok. Many tourists came to visits to Phitsanulok because of they can get many kind of products in one place and many tourists were accepted that the people service-minded to help each other.

\section{Recommendations}

From the result of the conclusion show that further study should focus on deal on package tours because this study found that the least factor is deal on package tours in Phitsanulok by domestic Thai tourists so it improves to be more reasonable price of deal on package and keep stable the good points that make the tourists impressed in Phitsanulok. Moreover, some suggestions from the tourists is mainly about the accessibility to the tourism areas for the disabled and senior tourists.

This is quite important and should be brought to the attention to tourism stakeholders in considering to improve this suggestion to be more efficient so it can attract more tourists not only domestic but also international.

\section{References}

[1] Bigne, J. E., Sanchez, M. I., \& Sanchez, J. (2001). Tourism image, evaluation variables and after purchase behaviour: inter-relationship. Tourism management, 22 (6), 607-616.

[2] Chen, C. F., \& Tsai, D. C. (2007). How destination image and evaluative factors affect behavioral intentions? Tourism management, 28 (4), 1115-1122.

[3] Crompton, J. L. (1979). Motivations for pleasure vacation. Annals of Tourism Research, 6, 408-424.

[4] Gardner, M. P. (1985). Mood states and consumer behavior: A critical review. Journal of consumer research, 12 (3), 281-300.

[5] Jacoby, J., \& Chestnut, R. W. (1978). Brand loyalty: Measurement and management.

[6] Lin, Y.-G., McKeachie, W. J., \& Kim, Y. C. (2003). College student intrinsic and/or extrinsic motivation and learning. Learning and individual differences, 13 (3), 251-258.

[7] Moutinho, L. (1987). Consumer behavior in tourism. European Journal of Marketing, 21 (10), 5-44.

[8] National Statistical Office. (2017). Situation to Domestic Traveler, Phitsanulok Province: 2009-2015. (online). Retrieved: http://web.nso.go.th/. Accessed on 29 April 2017.

[9] Oppermann, M. (2000). Tourism destination loyalty. Journal of travel research, 39 (1), 78-84.

[10] Parasuraman, A., Zeithaml, V. A., \& Berry, L. L. (1994). Reassessment of expectations as a comparison standard in measuring service quality: implications for further research. the Journal of Marketing, 111-124.

[11] Pearce, P. L. (1995). Pleasure travel motivation. In R. W. McIntosh, C. R. Goeldner, \& J. R. B. Ritchie (Eds.), Tourism: Principles, practices, philosophies. (167-178). New York: Wiley. 
[12] Rittichainuwat, B. N., Qu, H., \& Mongkhonvanit, C. (2007). A study of the impact of travel inhibitors on the likelihood of travelers' revisiting Thailand. Journal of travel \& tourism marketing, 21 (1), 77-87.

[13] Ryan, R. M. (2002). Overview of self-determination theory: An organismic dialectical perspective. Handbook of self-determination research, 3-33.

[14] Shanka, T., Ali-Knight, J., \& Pope, J. (2002). Intrastate travel experiences of international students and their perceptions of Western Australia as a tourist destination. Tourism and Hospitality Research, 3 (3), 245-256.

[15] Tourism Authority of Thailand. (2017). General Thailand. (online). Retrieved: https://www.tourismthailand.org/home. Accessed on 29 April 2017.
[16] Wang, X., Zhi, L. \& Müllen, K. (2008). Transparent, conductive graphene electrodes for dye-sensitized solar cells. Nano letters, 8 (1), 323-327.

[17] Weber, K. (1996). The assessment of tourist satisfaction using the expectancy disconfirmation theory: a study of the German travel market in Australia. Pacific Tourism Review, 14: 35-45.

[18] Woodside, A. G., Frey, L. L., \& Daly, R. T. (1989). Linking Sort/ice anlity, Customer Satisfaction, and Behavioral Intention. Journal of health care marketing, 9 (4), 5-17.

[19] Yamane, T. (1967). Statistics, An Introductory Analysis, $2^{\text {nd }}$ Ed., New York: Harper and Row. 